\title{
SITUAÇÕES E REPRESENTAÇÕES SOBRE ADOLESCENCIA, JUVENTUDE E VIOLENCIA: UM ESTUDO QUALITATIVO A PARTIR DA MÍDIA IMPRESA PARAENSE
}

\author{
Thaís Pimenta Pimentel ${ }^{1}$ \\ Lucia Isabel da Conceição Silva²
}

\begin{abstract}
RESUMO: O presente trabalho apresenta o recorte da pesquisa de TCC (Trabalho de Conclusão de Curso) situações e representações sociais na mídia impressa sobre adolescência, juventude e violência no cenário paraense. Com o objetivo de descrever as situações de violência envolvendo adolescentes e jovens veiculados na mídia impressa em Belém-Pa, analisando as representações sociais sobre essas situações que a mídia contribui ao divulgar. A metodologia utilizada foi pesquisa de enfoque qualitativo, sob o recorte bibliográfico e documental, tendo como documento o caderno policial do Jornal Diário ${ }^{3}$ no período 22 a 28 de Outubro de 2013. Os dados mostram que de acordo com a pesquisa os jovens envolvidos nesses atos violentos são em sua maioria homens entre 15 a 26 anos de idade, moradores de periferias e alguns reincidentes de outros crimes. Em relação à linguagem utilizada o estudo mostrou que há por parte da mídia uma preocupação em descrever detalhes referentes à brutalidade dos casos, além de utilizarem uma linguagem metafórica que contribui na construção de representações sociais que identificam um "jovem problemático", seja na condição de autor ou vítima nos casos violentos, não havendo uma preocupação em discutir o contexto dos casos.
\end{abstract}

PALAVRAS-CHAVE: Juventude. Representações Sociais. Violência. Mídia Impressa.

\section{INTRODUÇÃO}

A temática da violência e juventude tem sido muito discutida por vários segmentos da sociedade. Essa discussão se dá, em grande parte, pelo aumento de ocorrências de atos violentos envolvendo atores (juvenis) nos diferentes ambientes, seja no meio familiar ou na comunidade. A exemplo disso, a mídia - veículo importante de informação na sociedade - figura como grande divulgadora desses atos.

O fenômeno social da violência cresce na sociedade e não é "privilégio" apenas de um determinado grupo social, pelo contrário, atinge vários segmentos da sociedade, as populações

\footnotetext{
${ }^{1}$ Pedagoga, thaispimenta10@ hotmail.com, Universidade Federal do Pará/Belém.

${ }^{2}$ Doutorado em Psicologia (Teoria e Pesquisa do Comportamento) pela Universidade Federal do Pará, Brasil(2006) Professora Efetivo adjunto IV da Universidade Federal do Pará , Brasil.

${ }^{3}$ O jornal Diário do Pará tem 31 anos de existência. Fundado pelo jornalista Laércio Barbalho, no dia 22 de agosto de 1982, o jornal passou ao longo dos anos por várias transformações, tanto no aspecto editorial quanto gráfico, incorporando os benefícios das tecnologias mais modernas no setor de impressos. Extraído do site:< http://diariodopara.diarioonline.com.br/N-57404.html > acesso em: 15 out. 2013.
} 
mais carentes e as de classe média e alta, os locais públicos e os privados (ABRAMOVAY, 2002). Há um agravamento dessa realidade, pois devido à generalização desse fenômeno na sociedade hoje podemos dizer que não há grupos sociais protegidos, mesmos aqueles amparados com formas de proteção institucional e individual não estão isentos de sofrerem alguma forma de violência. Isso evidencia não restrição da violência a

grupos específicos, tais como de mulheres, grupo racial e etc. No entanto, percebemos que as diferentes formas e modalidades de violência se acentuam mais em determinados grupos que em outros.

Confirmando essa realidade de preocupação com as associações entre violência e juventude e ao mesmo tempo buscando formas para compreender e enfrentar essa realidade, Novaes (2009) ressalta que:

[...] buscava-se enfrentar a violência por meio da ideia de prevenção de delitos. Para os jovens considerados em situação de risco, foram reservados projetos específicos para conter a violência e para garantir sua ressocialização. As atividades culturais, neste contexto, foram vistas como uma importante via de contenção da violência juvenil. (NOVAES, 2009, p. 16).

Nesse sentido, para uma melhor compreensão é importante conceituarmos adolescência e juventude. Segundo Ferreira (1993), juventude é uma palavra que significa: idade jovem, mocidade, juventude ou pessoa jovem; é uma fase caracterizada por descobertas, ações, pensamentos revolucionários entre tantos outros. É onde começam os sonhos, planos, namoros, estudos, rebeldia, festas etc.

Recorrendo ao critério objetivo da idade, a Organização Pan-Americana da Saúde (OPAS), a Organização Mundial da Saúde (OMS) (1990), o Ministério da Saúde (MS) (1989) delimitam a adolescência entre 10 e os 19 anos e a juventude dos 15 aos 24 anos (ASSIS et al, 2005), sendo uma fase do desenvolvimento humano caracterizada por diversas mudanças físicas, psicológicas e sociais (SILVEIRA et al, 2011). Já o Estatuto da Criança e do Adolescente (ECA) no seu $2^{\circ}$ artigo do Título I - Das Disposições Preliminares, “considera adolescentes aqueles sujeitos entre 12 e 18 anos de idade" (BRASIL, 2008, p. 10) legitimando, portanto, este critério etário para definir adolescência no Brasil, obviamente que atravessado por características psicológicas e sociais. Esta legislação também teve papel fundamental no aumento da visibilidade da adolescência como segmento populacional alvo de garantias e proteção jurídica e social, como etapa especial de desenvolvimento. 
Dessa forma, é possível observar que adolescência e juventude são vistas como uma parte do ciclo da vida e que na maioria dos estudos e pesquisas, apesar de utilizarem o ponto de vista etário para sua caracterização, o fazem sempre associando uma diversidade de fatores relativos aos processos psicológico, social, biológico que atravessam a construção desses sujeitos em cada período e medeiam os confrontos e negociações na construção de sua personalidade e identidade.

\section{OBJETIVOS}

O objetivo geral foi descrever as situações de violência envolvendo adolescentes e jovens veiculados na mídia impressa em Belém - Pará, analisando as representações sociais sobre essas situações que a mídia contribui ao divulgar. Para isso, também buscou os objetivos específicos abaixo:

- Mapear as situações de violência envolvendo adolescentes e jovens relatadas num jornal de grande circulação na cidade;

- Descrever o perfil dos adolescentes e jovens envolvidos e o tipo de envolvimento na situação de violência;

- Analisar a linguagem utilizada para descrever os sujeitos e o envolvimento;

- Analisar as representações sociais sobre violência reveladas nas notícias.

\section{METODOLOGIA}

A pesquisa foi realizada no período no período de 22 a 28 de Outubro de 2013. Optou- se por uma pesquisa de enfoque qualitativo, sob o recorte bibliográfico e documental. A justificativa para esta opção ocorre porque, segundo Gil (2002) tem como objetivo proporcionar maior aproximação com o problema, com o intuito a tornálo mais claro ou a produzir hipóteses. Pretende-se uma análise qualitativa por considerar, segundo Minayo (2012, p.21) que este é um tipo de pesquisa que "trabalha com universo de significados, dos motivos, das aspirações, das crenças, dos valores e das atitudes".

Outro procedimento é a pesquisa documental, sendo neste caso, a análise de jornais impressos. Foram analisadas reportagens do Caderno Polícia de um dos jornais de grande circulação na Cidade de Belém - Pará sendo este: o Diário do Pará . Foram coletadas 07 edições diárias no período de 22 a 28 de Outubro de 2013, sendo 
selecionadas todas as reportagens sobre violência envolvendo adolescentes e jovens na faixa etária de 14 a 29 anos.

Seguindo esse critério, foram selecionadas 37 reportagens relatando diversas situações de violência, tais como roubo, cárcere privado, assassinato, tentativa de homicídio, agressão física, assalto a mão armada, tráfico de drogas e porte ilegal de arma.

Os dados foram sistematizados em uma planilha de acordo com os seguintes itens: título da reportagem, subtítulo, envolvidos autor e vítima (perfil), descrição dada pela mídia, atuação (desfecho do caso e encaminhamento dado) e observações.

\section{RESULTADOS E DISCUSSÃO}

O mapeamento das noticias mostrou no período de 22 a 28 de outubro de 2013, 37 casos de violência, sendo 01 por tentativa de homicídio, 12 por assalto à mão armada, 03 por assalto seguido de morte, 04 por tráfico (suspeita de tráfico), 01 por porte ilegal de arma, 01 por porte de objeto roubado e, por último, 02 por suspeita de assassinatos.

A partir do mapeamento já se pode fazer as primeiras discussões, primeiramente sobre o local de ocorrência dos casos de violência. A maior parte das ocorrências aconteceu nas periferias da grande Belém, que já são conhecidas por sofrerem com problemas de saneamento básico, saúde, lazer e educação, uma série de problemas que de várias formas, vulnerabilizam a população dessas áreas, como anteriormente apontadas em pesquisas.

Nos casos de assaltos, os envolvidos na sua maioria foram jovens do sexo masculino entre 18 a 23 anos e adolescentes de 15 a 17 anos também do sexo masculino. Sendo 20 pessoas do sexo masculino e 09 do sexo feminino na situação de autores. Na situação de vítimas, foram 06 do sexo masculino e 03 do sexo feminino. Nas notícias muitos já eram conhecidos no meio criminal por terem participado de outros crimes, como envolvimento com tráfico de drogas, assaltos e em alguns casos são suspeitos de assassinato.

Sobre a linguagem utilizada para descrever os sujeitos e o envolvimento. A partir da análise das reportagens também podemos perceber que a mídia utiliza uma linguagem "própria" para descrever os sujeitos envolvidos nos atos violentos e o ato em 
si. Evidenciamos expressões com o intuito de chamar atenção de um determinado público. Essa linguagem é percebida desde a manchete da reportagem que vem em destaque com letras "garrafais" e com títulos contendo palavras e expressões com sentidos diferenciados. Algumas manchetes:

$\checkmark \quad$ “Madrugada Sangrenta” (DIÁRIO DO PARÁ, 22 out. 2013).

“Assaltante é caçado pela polícia após assalto" (DIÁRIO DO PARÁ, 25 out. 2013).

“Piripiri' é caçado por mototaxistas e morto a pauladas" (DIÁRIO DO PARÁ, 23 out. 2013).

$\checkmark \quad$ "Homem morre trucidado por mototaxistas" (DIÁRIO DO PARÁ, 23 out. 2013)

“Assaltante de estudante terá lição na cadeia” (DIÁRIO DO PARÁ, 25 out. 2013).

"Bandido morre ao topar com os heróis do povo" (DIÁRIO DO PARÁ, 28 out. 2013).

$\checkmark \quad$ "Executado com quatro tiros no 'Bengola"” (DIÁRIO DO PARÁ, 28 out. 2013).

$\checkmark \quad$ "Homem é executado no Guamá com oito balaços". (DIÁRIO DO PARÁ, 26 out. 2013).

"Suspeito de roubo é executado com três tiros" (DIÁRIO DO PARÁ, 26 out. 2013).

Em relação à descrição dos atos violentos, a mídia parece sempre buscar passar detalhes do ocorrido referente a quantidade de tiros, facadas e etc., procurando pormenorizar a brutalidade do ato. Isso é bem visível nos trechos abaixo:

$\checkmark \quad$ “[...] Dois ciclistas, um deles armado com um revólver calibre 38, dispararam sem dó nem piedade quatro tiros contra a vítima que morreu na passagem Santa Rita [...]” (DIÁRIO DO PARÁ, 28 out. 2013).

$\checkmark \quad$ “[...] Os populares, no entanto, imobilizaram os suspeitos e partiram para cima com golpes de terçado e pauladas. O assaltante não sobreviveu" (DIÁRIO DO PARÁ, 28 out. 2013). 
Assim, a mídia contribui na construção de representações sociais de um jovem "problemático", pois não discuti em suas reportagens o contexto dos atos violentos, ou seja, não debate que é esse jovem (agressor ou vitima) e procura enfatizar a brutalidade dos casos, além em algumas reportagens uma linguagem preconceituosa. E em algumas manchetes a mídia parece julgar os casos e sentenciar os mesmo.

\section{CONCLUSÕES}

A pesquisa revelou através da análise do jornal impresso eventos que confirmam o perfil da maioria dos jovens sendo eles os que mais sofrem com o fenômeno da violência, e são apresentados desde o início do estudo na faixa etária entre 15 a 26 anos, do sexo masculino, moradores de periferia e que a mídia possui um trato particular de apresentar as situações de violência envolvendo os adolescentes e jovens paraenses. Utilizando-se de uma linguagem própria para descrever o ato violento, destaca a brutalidade dos envolvidos nesses atos sem dialogar sobre o contexto. Além de apresentar sempre uma representação social de um "jovem problemático".

Dito isso, podemos afirmar que o fato da maioria dos casos apresentados envolverem adolescentes e jovens, seja na condição de vítima ou de autor dos atos violentos relatados no mapeamento da violência morarem em grande parte nas periferias, não pode ser um fato despercebido. Pelo contrário, tal condição só vem confirmar a falta de políticas públicas e planejamentos para um desenvolvimento pleno dessa categoria que precisa ser melhor pensada, elaborada e socializada por parte dos órgãos públicos para enfrentamento da problemática e diminuição de sua condição de vulnerabilidade social. E a mídia como grande forma de divulgação de massas não se preocupa com essas especificidades na hora de divulgar suas reportagens.

\section{REFERENCIAS}

ABRAMOVAY, Miriam. Juventude, violência e vulnerabilidade social na América Latina: desafios para políticas públicas / Miriam Abramovayet alii. - Brasília, UNESCO, $\quad$ BID, 2002. 192 p. Disponível em: <http://unesdoc.unesco.org/images/0012/001271/127138por.pdf>. Acesso em: 18 set. 2014.

ASSIS, Simone G.; DESLANDES, Suely F.; SANTOS, Nilton C. Violência na adolescência: sementes e frutos de uma sociedade desigual. In: BRASIL, Ministério da Saúde. Secretaria de Vigilância em Saúde. Impacto da violência na saúde dos 
brasileiros. Brasília: Ministério da saúde, 2005. p.79-115.

BRASIL, Estatuto da criança e adolescente. Brasília: IMAS, 2008.

CASTRO, Mary G. Quebrando mitos: juventude, participação e políticas. Perfil, percepções e recomendações dos participantes da $1^{\circ}$ Conferência Nacional de Políticas Públicas de juventude; resumo executivo / Mary Garcia Castro e Miriam Abramovay. Brasília: RITLA, 2009. Disponível em:

<http://www.acervo.epsjv.fiocruz.br/beb/textocompleto/009501>. Acesso em: 14 nov. 2014.

FERREIRA, Aurélio Buarque de Holanda. Minidicionário da Língua Portuguesa. 3ed. Rio de Janeiro: Nova Fronteira, 1993.

GIL, Antonio Carlos. Como elaborar projetos de pesquisa.4ed.São Paulo: Atlas, MINAYO, Maria Cecília de Souza. Pesquisa social: teoria, método e criatividade. 23. ed. Petrópolis, RJ: Vozes, 2012.

SILVEIRA, Luciana Ramos et al. Adolescer cidadão: percepção da cidadania no cotidiano adolescente. Revista eletrônica de enfermagem. Santa Catarina, p. 537-545, jul-set, $\quad 2011 . \quad$ Disponível em:< http://www.revistas.ufg.br/index.php/fen/article/view/9745> Acesso em: 9 de nov. 2014. 